Association for Information Systems AIS Electronic Library (AISeL)

BLED 2003 Proceedings

BLED Proceedings

December 2003

\title{
Economic and Social Analysis of the Adoption of B2B Electronic Marketplaces: A Case Study in the Australian Beef Industry
}

Caroline Driedonks

Department Business Information Systems, University of Twente

Shirley Gregor

School of Business and Information Management, Australian National University

Arjen Wassenaar

Department Business Information Systems, University of Twente

Follow this and additional works at: http://aisel.aisnet.org/bled2003

\section{Recommended Citation}

Driedonks, Caroline; Gregor, Shirley; and Wassenaar, Arjen, "Economic and Social Analysis of the Adoption of B2B Electronic Marketplaces: A Case Study in the Australian Beef Industry" (2003). BLED 2003 Proceedings. 21.

http://aisel.aisnet.org/bled2003/21

This material is brought to you by the BLED Proceedings at AIS Electronic Library (AISeL). It has been accepted for inclusion in BLED 2003

Proceedings by an authorized administrator of AIS Electronic Library (AISeL). For more information, please contact elibrary@aisnet.org. 


\title{
$16^{\text {th }}$ Bled eCommerce Conference \\ eTransformation
}

Bled, Slovenia, June 9 - 11, 2003

\section{Economic and Social Analysis of the Adoption of B2B Electronic Marketplaces: A Case Study in the Australian Beef Industry}

\author{
Caroline F. Driedonks \\ Department Business Information Systems, University of Twente, The Netherlands \\ CDriedonks@hotmail.com

\section{Shirley Gregor} \\ School of Business and Information Management, Australian National University, Australia \\ Shirley.Gregor@Anu.edu.au
}

\section{Arjen Wassenaar}

Department Business Information Systems, University of Twente, The Netherlands D.A.Wassenaar@sms.utwente.nl

\begin{abstract}
The purpose of this paper is to investigate factors that affect the rate of adoption of $B 2 B$ electronic marketplaces as innovations. The paper reports a case study of AuctionsPlus, an electronic marketplace in the Australian beef industry. Two existing theories were drawn upon to explain the relatively slow adoption of this system. Kambil and van Heck's model of exchange processes offers a primarily economic view at the level of key stakeholder groups. Rogers' diffusion theory gives a more social viewpoint, at the level of the individual stakeholders. It was found that key stakeholder groups do not appear to be substantially worse off with AuctionsPlus from an economic exchange-process point of view. Considering the social and political dimensions of electronic marketplaces, however, contributes to further understanding of the case. Important influences appear to be loss of social capital, the nature of communication channels, time taken to reach critical mass, and the power of one group originally not recognized as a key player - the stock and station agent intermediaries.
\end{abstract}

Key words: electronic markets, adoption of innovations 


\section{Introduction}

The research presented in this paper focuses on the adoption of business-to-business (B2B) electronic marketplaces, and more specifically, the factors that lead to the success of an electronic marketplace in opposition to existing exchange mechanisms. The study was motivated by questions concerning the relatively low rate of use of an electronic marketplace in the Australian beef industry and is discussed in detail by Driedonks (2003).

Several exchange methods exist in this industry, as shown in Figure 1. The major exchange methods are the traditional saleyard auctions and the over-the-hooks method. The electronic marketplace, AuctionsPlus, is an alternative to these traditional methods. Adoption of AuctionsPlus, however, has not been as widespread as originally envisaged, even after a relatively long period of time. The case of AuctionsPlus offers the opportunity to gain insights into the reasons behind the success or otherwise of B2B marketplaces.

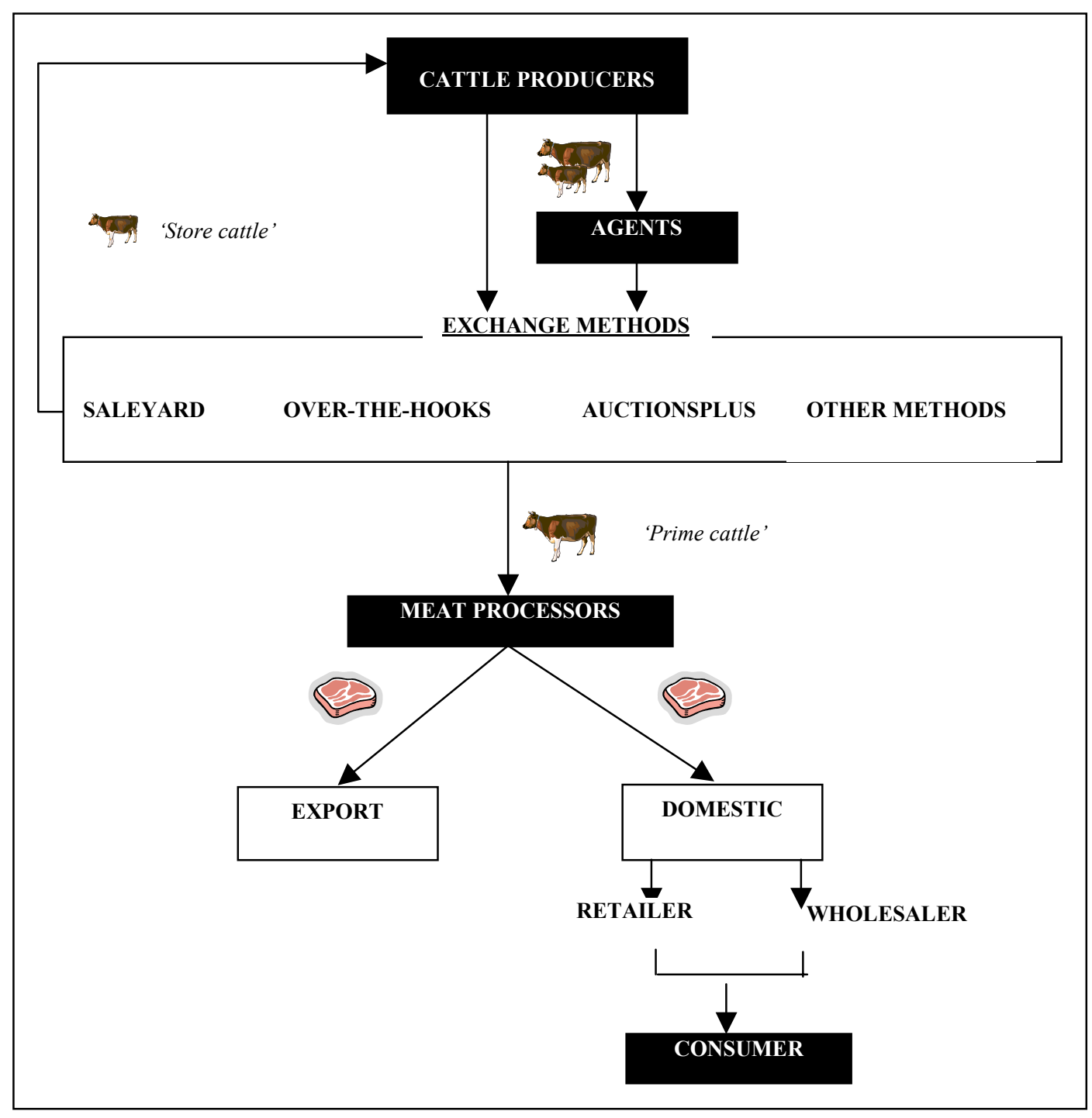

Figure 1: Australia's beef supply chain 
AuctionsPlus is a computer-based auction system and claims to combine the advantages of the major traditional exchange methods (AuctionsPlus, 2002). The Australian Meat and Livestock Cooperation (AMLC) launched this system under the name of Computer Aided Livestock Marketing (CALM) in 1987. CALM claimed to "provide a system for buying and selling cattle, sheep, lambs and pigs, on the basis of an objective description, while the stock remains on the property or feedlot. Buyers can bid from anywhere in Australia. CALM combines the advantages of auction selling with the efficiency of sale by description" (Clarke \& Jenkins, 1993, p. ). In 1995 the major stock-agent companies, WesFarmers, Elders Landmark and Roberts together took over CALM, centralised the organisation and changed its name to AuctionsPlus. It is remarkable that this marketplace has never really burgeoned in terms of adoption. The number of registrations has increased over the years, but the number of users is still not much higher than in 1988, when the system was just launched (Driedonks, 2003). The cattle producers and meat processors, who are potential users, have tended to continue with the major traditional methods for trading cattle - saleyard auctions and over-the-hooks. Previous research on the system in its CALM form include papers by Clarke and Jenkins (1993) and Fong, Fowler and Swatman (1998). It appears timely to carry out a further investigation of this system.

The traditional saleyard auctions are still the most common method of selling cattle in Australia with $48 \%$ of the sales in 1999-2000 (Riley et al., 2001). Often agents sell livestock on behalf of cattle producers for a commission. Producers pay a yard fee, industry and government levies and freight costs. The traditional strengths of saleyards are that buyers can view the animals they are purchasing and the pricing is usually very competitive, with 'lots' of animals being sold to the highest bidder. The sale price may be on a per-head or live-weight basis. There are negatives associated with saleyards though. Animals can get stressed during and after transport, which may affect meat quality. Saleyards can be quality assurance accredited with the National Saleyard Quality Assurance scheme, or NSQA. This quality assurance aims to improve animal welfare and reduce the stresses that might affect meat quality, taking into account many factors including livestock reception procedures and yard construction.

The second most common method of exchange is over-the-hooks marketing, with $26 \%$ of sales in 1999-2000 (Riley et al., 2001). This method involves direct selling from the cattle producer to a meat processor. Payment is based on the Hot Standard Carcase Weight (HSCW) after slaughtering and various other measurements such as fat percentage, plus the value of the skin or hide. Over-the-hooks marketing is market specific and ensures that producers get paid for exactly what they produce. Producers choose which market specifications they will meet and negotiate a price. The actual price paid depends on whether specifications are met after slaughter in terms of weight, fat scores, skin quality and so on. The system emphasizes guidelines regarding transport (loading, unloading, time and cleanliness), handling, lairage, watering, feed, stress, and ensures constructive communication and feedback.

\section{Aim and Structure of This Paper}

The question that gave rise to the research presented in this paper was whether the adoption of B2B electronic marketplaces could be explained primarily in terms of relative advantage offered by the innovation (an economic explanation) or whether other social factors such as perceptions of the innovation play an important role (a social explanation). Thus the aim of the paper is to investigate the economic and social factors that affect the rate of adoption of $B 2 B$ electronic marketplaces as innovations. 
A $B 2 B$ electronic marketplace is defined as an Internet based institution using market mechanisms to mediate transactions between businesses (Kaplan \& Sawhney, 1999). An innovation is an idea, practice, or object that is perceived as new by an individual or other unit of adoption (Rogers, 1995). The rate of adoption is the relative speed with which an innovation is adopted by members of a social system, which is generally measured as the number of individuals who adopt a new idea in a specified period, such as each year (Rogers, 1995). In this paper adoption means the range of behaviours from the decision to use an innovation to full and regular use of the innovation and rejection means the decision not to use the innovation at all.

The research focuses on both economic and social explanations for individual and group use of B2B electronic marketplaces, which are perceived as a new way of trading (an innovation). The study is significant as there is a paucity of theory-based research on the adoption of electronic marketplaces, the Kambil and van Heck (1998) study being a notable exception. These authors called for further empirical investigation of the framework they proposed. This study answers their suggestion by applying their framework to a different industry context, and supplementing their framework with an analysis that includes social processes.

The following section 3 presents the theoretical background and section 4 introduces the initial research model that guided the investigation. In section 5, the research methodology is explained. Section 6 presents the case study findings. In section 7 conclusions are drawn regarding the case study and the research model in general. Final remarks are made in section 8.

\section{Theoretical Background}

Many different definitions of markets exist in the literature. Koppius attempts to classify market theories by distinguishing markets along two separate dimensions; (i) whether a market is viewed as a state or a process and (ii) whether markets primarily are viewed as economic allocation mechanisms or as social structures (Koppius, 2002). Concerning the latter distinction, many definitions of markets focus on fulfilling the role of an allocation mechanism rather than a social mechanism. Wigand, Picot and Reichwald for instance define a market as "an economic location on which the supply and demand for goods meet, enabling exchange processes" (Wigand, Picot, \& Reichwald, 1997). Kambil and van Heck also focus on this economic allocation aspect of markets (Kambil \& van Heck, 1998).

Koppius notes that the social aspect of markets is often underexposed. He states that "Markets are social institutions that facilitate exchange by means of competition. The primary goal of a market is to solve the problems of resource allocation (who gets what) and price determination (at which price)" (Koppius, 2002, p. 1).

Two existing theories are drawn upon to explain the adoption of B2B electronic marketplaces as an innovation. These theories were chosen because they offer complementary perspectives in two respects: (i) an economic view versus a more social view on adoption behaviour, and (ii) analysis at the group or at the individual level.

The first theory is Kambil and van Heck's process-stakeholder framework (Kambil \& van Heck, 1998). Kambil's generalizable model of exchange processes, in which five basictrade processes and five trade-context processes are distinguished (Kambil \& van Heck, 1998), forms a basis for this process-stakeholder framework. 
- Basic-trade processes include the processes required in all transactions of goods and services: search, valuation, logistics, payment and settlements, and authentication.

- Trade-context processes facilitate and enable or reduce the costs of or 'frictions' in the basic processes: communication and computing, product representation, legitimation, influence and dispute resolution.

Kambil and van Heck use the generalizable model of exchange processes to build a process-stakeholder analysis framework with the aim of comparing traditional markets and IT-enabled markets in the same market. This categorization allows systematic identification of processes affected by a specific administrative or technological innovation and enables systematic examination and representation of the impacts of IT across interdependent processes and stakeholder groups in an electronic market.

Kambil and van Heck applied this process-stakeholder framework to analyze a number of information technology initiatives in the Dutch flower markets using cross-case analysis and studying success and failures in the introduction of new IT-based trading mechanisms in these markets. One of the testable propositions formulated as an outcome of this study is:

"Market organizations are the meeting point for multiple stakeholders: buyers, sellers, and intermediaries with conflicting incentives. Given existing or market alternatives, no new IT-based initiative is likely to succeed if any key stakeholder is worse off after the ITenabled innovation" (Kambil and van Heck, 1998, p. 16).

In other words, Kambil and van Heck state that the relative (economic) advantage of an IT-enabled innovation plays an important role in its adoption.

The second theory used here is Rogers' diffusion of innovations theory (Rogers, 1995). Rogers states:

"The innovation decision process consists of the series of actions and choices over time through which an individual (or organization) evaluates a new idea and decides whether or not to incorporate the innovation into ongoing practice" (Rogers, 1995, p. 161).

This innovation behaviour follows from the uncertainty that is inherently involved in deciding about a new alternative relative to those previously in existence. The perceived newness of an innovation, and the uncertainty associated with this newness, is a distinctive aspect of innovation decision-making. Rogers distinguishes five steps and stages of the innovation decision process. The first step, knowledge, occurs when an individual is exposed to an innovation's existence and gains some understanding of how it functions. At the following stage, persuasion, the individual forms a favourable or unfavourable attitude towards the innovation. Next, during the decision, the individual engages in activities that lead to a choice to adopt or reject the innovation. The implementation occurs when an individual puts an innovation into use. Finally, at the confirmation stage, the individual seeks reinforcement of an innovation decision already made, or reverses a previous decision to adopt or reject the innovation if exposed to conflicting messages about the innovation.

Rogers argued that the rate of adoption of an innovation is determined by the perceived attributes of the innovation (relative advantage, compatibility, complexity, trialability, and observability), the type of innovation-decision (optional, collective, authority), communication channels (mass media or interpersonal), the nature of the social system and the extent of change agents' promotion efforts.

Other models for technology acceptance at the level of individuals exist. A broad intention-based theory is the Theory of Reasoned Action (TRA) (Fishbein and Azjen, 
1975) which proposes that beliefs influence attitudes, which in turn shape intentions, which then guide or dictate behaviours. The Technology Acceptance Model (TAM) was derived from TRA specifically for explaining and predicting individual acceptance of computer technology (Davis, 1989; Davis, Bagozzi, and Warshaw, 1989). Davis (1989) saw TAM as compatible with Rogers' diffusion theory, his aim being to provide better measures for predicting and explaining use, with central variables being perceived usefulness (relative advantage) and ease of use (lack of complexity). Rogers' theory is used here as it gives a broader picture of the innovation process and the role of communication channels, change agents and social systems.

\section{Research Model}

In order to investigate the economic and social factors affecting the rate of adoption of B2B electronic marketplaces, the research model shown in Figure 2 is developed. This model integrates elements of both theories discussed above. The theories complement each other as one focuses on the innovation's net benefit at the level of key stakeholder groups and the other focuses on the perceptions of individual potential users. Together these theories offer a potential explanation for the adoption and success of B2B electronic marketplaces.

The research model explains behaviour at two levels:

\section{- Level 1 - Net benefits for key stakeholder groups}

At this level Kambil and van Heck's economic-political process-stakeholder theory shows how relative advantage within basic-trade and trade-context processes for key stakeholder groups when using the IT-enabled innovation (a B2B electronic marketplace) influence adoption and use.

\section{- Level 2 - Perception of individual potential users}

At this level Rogers' social-political diffusion of innovations theory gives an understanding of how the actions and perceptions of individuals and organizations interact in a social process over time to influence the uptake of a B2B electronic marketplace.

Analysis at these two levels is expected to contribute to an explanation of a B2B electronic marketplace's rate of adoption, and therefore partially its success. This research model was used as an initial guide for the case study.

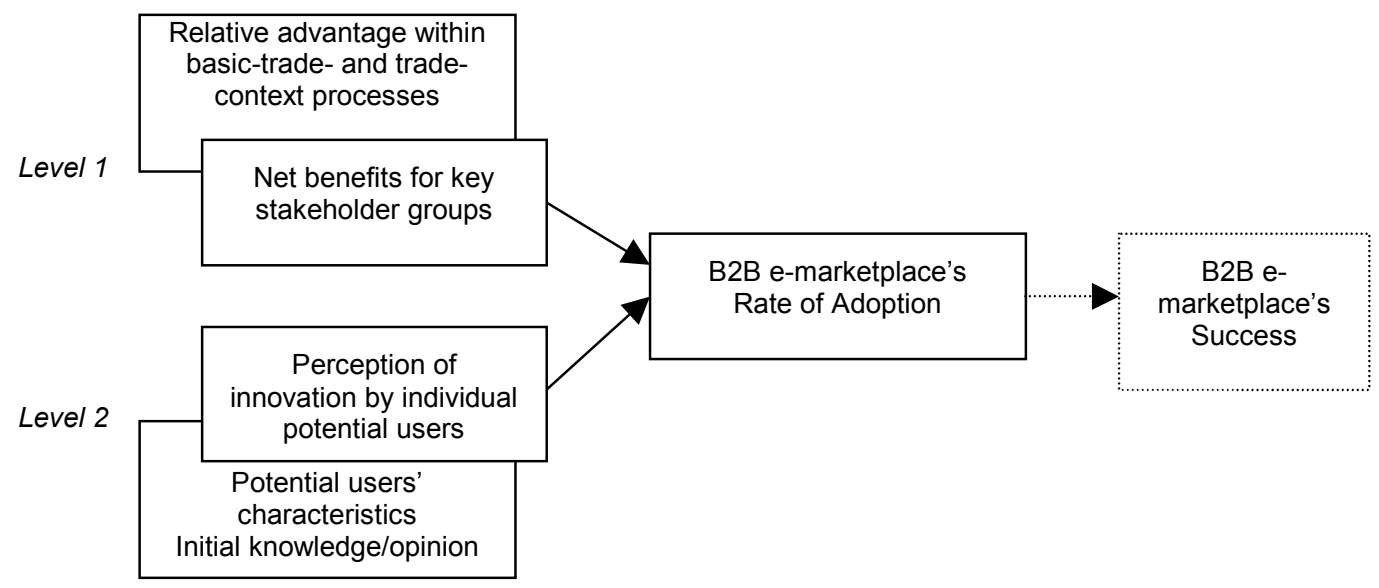

Figure 2: Research Model 


\section{Research Methodology}

The type of research question asked as a main question can be seen as a 'why-question'; exploring 'what factors affect the rate of adoption of B2B electronic marketplaces as innovations' can be translated into why potential users decide to use or not use B2B electronic marketplaces. A case study strategy is indicated to explore the answers to this question (Yin \& Campbell, 1989). Data was gathered from interviews, direct observation of auctions (both electronic and saleyard), web sites, reports and other archival sources. Interviewees were given the opportunity to check and amend the transcripts of their interviews. The data was analysed using the guidelines suggested by Miles and Huberman (1994) for qualitative data analysis. Interview transcripts were analysed for themes and patterns that concerned the primary research question, using the research model as a framework.

Analysis occurred at two levels:

At Level 1, the net benefits for key stakeholder groups of competing exchange mechanisms were analysed in terms of the Kambil and van Heck (1998) framework. Twelve people were interviewed, including two saleyard managers, three industry experts, five cattle producers who used AuctionsPlus, and two AuctionsPlus managers.

At Level 2, the perceptions of the innovation and the innovation process by individuals and organizations were analysed. Seventeen people were interviewed, including five cattle producers who adopted AuctionsPlus, five cattle producers who rejected AuctionsPlus, one meat processor who adopted AuctionsPlus and one meat processor who rejected AuctionsPlus, and five industry experts.

\section{Findings}

An overview of findings is presented for both levels of analysis.

- Level 1 - Net benefits for key stakeholder groups

At Level 1, Table 1 shows AuctionsPlus compared with saleyard exchange and Table 2 shows AuctionsPlus compared with over-the-hooks exchange. These tables in summary present the process-stakeholder framework of Kambil and van Heck (1998) used for analysis by Driedonks (2003). This framework depicts ten processes involved in a marketplace exchange. Analysis of the costs and benefits related to each process in different marketplaces allows for systematic comparison of the advantages and disadvantages accruing to different stakeholders. This analysis has primarily an economic focus.

Table 1 shows selling cattle producers have overall positive net benefits from the AuctionsPlus system compared with the traditional saleyard auction. Keeping cattle on property till sale and the possibility of setting a reserve price improves their negotiating position considerably. Selling cattle producers do not need to freight cattle into the saleyard, which lowers costs depending on the distance to the nearest saleyard. In return, assessment has to be arranged and paid by the selling party. These costs generally turn out lower than freight costs and saleyard fees together. The assessment of cattle gives cattle producers feedback on their production. Additionally, the AuctionsPlus system gives access to more buyers all over Australia and because of more competition higher prices can be generated through this auction system. Keeping cattle on property till sale 
and the possibility of setting a reserve price improves their negotiating position considerably, also leading to higher prices, compared with sending cattle to the saleyard.

Table 1: Benefits and Costs of AuctionsPlus for Different Stakeholder Groups Compared with Saleyard Exchange

\begin{tabular}{|c|c|c|}
\hline \multirow[b]{2}{*}{ Outcome category } & \multicolumn{2}{|c|}{ Stakeholder groups } \\
\hline & Selling cattle producers & $\begin{array}{l}\text { Buyers (producers and } \\
\text { processors) }\end{array}$ \\
\hline \multicolumn{3}{|c|}{$\begin{array}{l}\text { (a) Basic-trade processes (search, valuation, logistics, payment and settlements, and } \\
\text { authentication) }\end{array}$} \\
\hline Benefits & $\begin{array}{l}\text { Lower search costs } \\
\text { Better negotiating position } \\
\text { Access to more buyers } \\
\text { More competition among buyers } \\
\text { No saleyard fees } \\
\text { No freight costs } \\
\text { Higher prices }\end{array}$ & $\begin{array}{l}\text { Lower search costs } \\
\text { Less time-consuming } \\
\text { Better planning } \\
\text { Access to wider range of } \\
\text { sellers } \\
\text { Better quality (less chance } \\
\text { of bruising, stress and } \\
\text { diseases) }\end{array}$ \\
\hline Costs & & $\begin{array}{l}\text { Higher prices } \\
\text { Freight costs }\end{array}$ \\
\hline \multicolumn{3}{|c|}{$\begin{array}{l}\text { (b) Trade-context processes (communication and computing, product representation, } \\
\text { legitimation, influence and dispute resolution) }\end{array}$} \\
\hline Benefits & $\begin{array}{l}\text { Market insight } \\
\text { Feedback on cattle production }\end{array}$ & $\begin{array}{l}\text { Market insight } \\
\text { Detailed cattle description } \\
\text { Standard product } \\
\text { assessment }\end{array}$ \\
\hline Costs & $\begin{array}{l}\text { Listing fee } \\
\text { Effort finding assessor } \\
\text { Assessment entry }\end{array}$ & $\begin{array}{l}\text { Learning costs } \\
\text { Internet connection costs } \\
\text { Not seeing cattle 'live' }\end{array}$ \\
\hline Overall net benefit & Positive & Neutral-positive \\
\hline
\end{tabular}

Buyers also benefit from using the AuctionsPlus system. Buying cattle through the system is less time-consuming and less expensive then going to the saleyard. In return, buyers pay freight costs and have Internet learning and connection costs. The AuctionsPlus system gives access to a wider range of sellers and their cattle all over Australia. More competition among buyers, however, may cause higher prices. A major benefit is that cattle get less stressed and bruised and the chance of diseases passed on to the cattle in saleyard holding pens is lower. Purchasers buy on the basis of detailed description instead of seeing the cattle. This method provides more objective, uniform information, but may yield less information than can be obtained by an experienced buyer who sights the cattle. On balance, it appears the outcome for buyers is neutral-positive net benefits. 
Table 2 shows cattle producers have overall net positive benefit from the AuctionsPlus system compared with using the over-the-hooks method, mainly because the system generates access to more meat processors all over Australia and there is competition among these meat processors. If AuctionsPlus is not used, and the cattle are not sent to a saleyard, the producer has to negotiate a price over the phone, most likely with a limited number of processors. The negotiating position is weaker, with reduced opportunities for price discovery, and thus prices are likely to be lower than with AuctionsPlus. When using AuctionsPlus, the sellers do not pay freight but do pay AuctionsPlus listing fees and assessment.

Table 2: Benefits and Costs of AuctionsPlus for Different Stakeholder Groups Compared with Over-the-hooks Exchange

\begin{tabular}{|c|c|c|}
\hline \multirow{2}{*}{ Outcome category } & \multicolumn{2}{|c|}{ Stakeholder groups } \\
\hline & Selling cattle producers & Buyers (processors) \\
\hline \multicolumn{3}{|c|}{$\begin{array}{l}\text { (a) Basic-trade processes (search, valuation, logistics, payment and settlements, and } \\
\text { authentication) }\end{array}$} \\
\hline Benefits & $\begin{array}{l}\text { Access to more buyers } \\
\text { Competition among buyers } \\
\text { No freight costs } \\
\text { Higher prices } \\
\text { (Price based on less accurate } \\
\text { system) }\end{array}$ & $\begin{array}{l}\text { Contribution to continuous } \\
\text { supply } \\
\text { Better production planning } \\
\text { Access to wider range of } \\
\text { sellers } \\
\text { (Price based on less accurate } \\
\text { system) }\end{array}$ \\
\hline Costs & $\begin{array}{l}\text { (Price based on less accurate } \\
\text { system) }\end{array}$ & $\begin{array}{l}\text { Auction on set time } \\
\text { Higher prices } \\
\text { Freight costs } \\
\text { (Price based on less accurate } \\
\text { system) }\end{array}$ \\
\hline \multicolumn{3}{|c|}{$\begin{array}{l}\text { (b) Trade-context processes (communication and computing, product representation, legitimation, } \\
\text { influence and dispute resolution.) }\end{array}$} \\
\hline Benefits & Market insight & $\begin{array}{l}\text { Market insight } \\
\text { Detailed cattle description }\end{array}$ \\
\hline Costs & $\begin{array}{l}\text { Listing fee } \\
\text { Effort finding assessor } \\
\text { Assessment entry }\end{array}$ & $\begin{array}{l}\text { Learning costs } \\
\text { Internet connection costs } \\
\text { Not seeing cattle 'live' }\end{array}$ \\
\hline Net benefit & Positive & Neutral \\
\hline
\end{tabular}

Prices are based on the assessment before the animal is sold, which is a less accurate method than the quality grid used by meat processors to assess the animal's yield after slaughter. This pricing method may be an advantage or not. 
The meat processors' overall net benefit from AuctionsPlus is neutral. Meat processors benefit from the AuctionsPlus system in having another purchasing method connecting them with producers all over Australia. Since meat processors are suppliers to retailers in a demand-driven chain, the opportunity of planning supply in advance is of great importance. Another advantage is that meat processors get a full description of the offered cattle before the sale. This gives them the possibility to bid on cattle that they consider most appropriate.

Usage of AuctionsPlus, however, costs meat processors a considerable amount. They have to arrange and pay freight of purchased cattle, pay Internet connection fees and may have learning costs. Prices paid may become higher because of competition. Meat processors don't see cattle before they buy and the quality of the cattle may change after the assessment.

From the process-stakeholder (economic) analysis, it is concluded that none of the key stakeholder groups (cattle producers and processors) as defined in this research is worse off using AuctionsPlus compared with traditional cattle exchange methods.

\section{- Level 2 - Perception of individual potential users}

At Level 2, Table 3 shows issues relating to the use of AuctionsPlus that were identified in the analysis of adoption and usage behaviour of individual entities using Rogers' diffusion theory to guide analysis. These issues emerged from qualitative analysis of interviews with industry participants. For each issue, factors that could lead to adoption and rejection were identified. These issues are both economic and social. The issues have been grouped according to the perspective from which they arose.

There were several issues arising from the perspective of the distinguishing characteristics of the cattle producers. The producers' location and distance to the nearest saleyards or abattoirs played a role in the adoption decision process. The larger this distance, the more the cattle producer is inclined to adopt AuctionsPlus. These factors explain why AuctionsPlus has more users in the northern and remote parts of Australia, where distances to saleyards are larger then in the more closely settled south-east regions. Cattle producers who were personally involved in industry politics, or cattle producers who are or were involved in CALM, for instance as an assessor, were more inclined to adopt the AuctionsPlus system. Although it would sound logical that IT innovativeness stimulates adoption of AuctionsPlus, a negative relationship was observed between IT innovativeness and adoption of the AuctionsPlus system. Cattle producers who used AuctionsPlus started using the Internet much later than those who did not. It is difficult to explain this finding. Possibly, early adopters of the Internet are located in areas with better telecommunications (less remote areas) and thus are also the enterprises which are closer to alternative, traditional market exchanges.

There were several issues arising from the perspective of the initial knowledge of the cattle producers. If initial knowledge was gained through personal communication about the system then adoption was stimulated. Cattle producers who are involved in political activities for instance are more confronted with the system and its users and are more open towards the system. Cattle producers who were only informed about the system by mass media were more inclined to reject. It is remarkable that most rejecters who initially had a positive opinion about AuctionsPlus rejected the system. It appears that these rejecters have not been persuaded to adopt because they are not connected to adopters who mostly are interconnected in political activities. The fact that respondents say they have trusted the AuctionsPlus system from the start shows there is no relation between trusting the system and adoption or rejection. In summary, most cattle producers initially 
were positive about AuctionsPlus and the ones who were informed about the AuctionsPlus system by personal (trustable) connections were inclined to adopt.

Table 3: Issues and Adoption/Rejection Factors for AuctionsPlus at the Individual Enterprise Level

\begin{tabular}{|c|c|c|c|}
\hline \multirow{2}{*}{ Perspective } & \multirow{2}{*}{ Issue } & \multicolumn{2}{|c|}{ Associated influence factors } \\
\hline & & Adoption factors & Rejection factors \\
\hline \multirow{3}{*}{$\begin{array}{c}\text { Characteristics of } \\
\text { the cattle } \\
\text { producers }\end{array}$} & Geography & $\begin{array}{l}\text { Large distance to } \\
\text { nearest } \\
\text { saleyard/abattoir }\end{array}$ & $\begin{array}{l}\text { Short distance to } \\
\text { nearest saleyard/ } \\
\text { abattoir }\end{array}$ \\
\hline & Background & $\begin{array}{l}\text { Involvement in } \\
\text { industry } \\
\text { politics/CALM }\end{array}$ & - \\
\hline & Internet adoption & $\begin{array}{l}\text { Later Internet } \\
\text { adoption }\end{array}$ & $\begin{array}{l}\text { Earlier Internet } \\
\text { adoption }\end{array}$ \\
\hline \multirow{3}{*}{$\begin{array}{c}\text { Initial knowledge } \\
\text { about } \\
\text { AuctionsPlus of } \\
\text { the cattle } \\
\text { producers }\end{array}$} & $\begin{array}{l}\text { Communication } \\
\text { channels used to } \\
\text { gain knowledge }\end{array}$ & $\begin{array}{l}\text { Personal } \\
\text { communication }\end{array}$ & $\begin{array}{l}\text { Mass communication } \\
\text { by media }\end{array}$ \\
\hline & Initial opinion & - & $\begin{array}{l}\text { Initial positive } \\
\text { opinion }\end{array}$ \\
\hline & Trust & Did not influence & Did not influence \\
\hline $\begin{array}{l}\text { Perceptions of } \\
\text { AuctionsPlus held } \\
\text { by the cattle } \\
\text { producers }\end{array}$ & $\begin{array}{l}\text { Heterogeneous } \\
\text { perceptions of } \\
\text { costs, negotiating } \\
\text { position, } \\
\text { competition }\end{array}$ & $\begin{array}{l}\text { All factors influenced } \\
\text { adoption and rejection }\end{array}$ & $\begin{array}{l}\text { All factors influenced } \\
\text { adoption and } \\
\text { rejection }\end{array}$ \\
\hline $\begin{array}{c}\text { Perceptions of } \\
\text { AuctionsPlus held } \\
\text { by the meat } \\
\text { processors }\end{array}$ & $\begin{array}{l}\text { Heterogeneous } \\
\text { perceptions of } \\
\text { efficiency }\end{array}$ & $\begin{array}{l}\text { Influenced adoption } \\
\text { and rejection }\end{array}$ & $\begin{array}{l}\text { Influenced adoption } \\
\text { and rejection }\end{array}$ \\
\hline \multirow{3}{*}{$\begin{array}{l}\text { Experts' insights } \\
\text { on AuctionsPlus } \\
\text { rejection }\end{array}$} & Social system & - & $\begin{array}{l}\text { Social network found } \\
\text { in traditional saleyard }\end{array}$ \\
\hline & Critical Mass & - & Not enough users \\
\hline & Stock Agents & - & Discouraging \\
\hline
\end{tabular}

There were several issues arising from the perspective of cattle producers' perceptions of AuctionsPlus. The results concerning potential users' perceptions showed that the potential users group is heterogeneous in many ways. Perceptions differed among potential users. Factors that directly stimulated decisions to adopt at the same time stimulated others to reject the AuctionsPlus system. Costs, negotiating position and competition were factors that had both negative and positive influence on adoption. Some cattle producers perceived the system as too expensive to use and stated there are not enough buyers in the system, which causes lack of competition. On the other hand, adopters were initially stimulated to adopt because they perceived lower costs and were 
attracted by gaining access to more buyers all over Australia, which would increase competition and generate higher prices.

The main issue arising from the perspective of meat processors was efficiency, which had both negative and positive aspects. One meat processor rejected because using the system was perceived as too time-consuming, while the meat processor who adopted perceived the system as an efficient supply method.

Interviews with industry experts showed they identified several issues affecting adoption. These experts included the president of the stock and station agents association, the CEO of the saleyard operators association, two ex-CALM employees, and a government representative. These experts all had many years of industry experience and an overview of the different stakeholders involved. These attributes give a good basis for deep insight into the relevant issues. They identified the nature of the social system in the Australian cattle industry as a strong influence on rejection of the system. Many cattle producers do not feel any need to change their ways of doing business. In addition, the social aspect of traditional saleyard auctions is a contribution to their social life, providing an opportunity to meet and socialize with peers. Otherwise, many producers have a fairly isolated existence in remote locations with social opportunities restricted by geography and very long working hours.

Experts believed that usage of AuctionsPlus was just below or 'on the edge' of critical mass, which varies among different auctions. This outcome is significant, as the system has been running for about fifteen years. The lack (or perception of a lack) of critical mass no doubt influences adoption of the system. One expert commented that it is "a chicken and egg" problem - most people don't want to use CALM until enough people use it.

The experts had an interesting view on the influence stock agents had on the adoption of AuctionsPlus. Agents are the intermediaries who facilitate sales of cattle through saleyards, earning a commission on the number of cattle sold and the price they reach. These agents advise the producers as to when their cattle are ready for sale, what price they are likely to fetch and may assist with rounding up the animals and arranging transport to the market. From this traditional role, agents have considerable influence over the producers. The agents often provide a very important social and commercial link between the relatively isolated cattle producer, his industry group and the outside world. The experts believed that the agents were discouraging usage of the AuctionsPlus system. Even the company owning AuctionsPlus, which employs many stock agents, was believed not to be stimulating adoption of AuctionsPlus strongly. Note that the stock agents were not identified as key stakeholders in the analysis that was carried out at Level 1. Obviously, the agents are worse off economically if cattle are sold through AuctionsPlus as they lose commissions. As an industry segment, the stock agents may not be regarded as "key stakeholders" as they are intermediaries, rather than players with a large economic investment and thus obvious explicit power in the industry. Nevertheless, it appears from social and historical reasons the stock agents may have more power and influence than is immediately apparent.

An attempt has been made to explain AuctionsPlus' low rate of adoption on two levels. Although on the economic level 1 no key stakeholder groups are worse off using AuctionsPlus, its rate of adoption is rather low. Placing the aspects in a social context on level 2 contributes much to the explanation of the relatively low take-up rate. 


\section{Conclusions and Discussion}

In this paper the question of what economic and social factors affect the rate of adoption of B2B electronic marketplaces as innovations is addressed. The research model formulated to investigate these factors combines economic and social exploratory theories.

Major differences between these theories lie in explaining rate of adoption on the basis of relative advantage on stakeholder group level and explaining this rate on the basis of perception on individual (enterprise) level.

\subsection{Conclusions Regarding the Case Study}

1. From the AuctionsPlus process-stakeholder analysis it can be concluded that economic factors do not fully explain rate of adoption. Although the key stakeholder groups' net benefits are neutral or positive, most individual potential users have decided not to adopt the AuctionsPlus system. Relative advantage on stakeholder group level does not mean relative advantage for each individual potential user. The cattle producers' group in the AuctionsPlus case is heterogeneous; for instance one's background plays an important role in relative advantage and especially in its perception. From a social view on the individual level it is explained why the innovation did not succeed in terms of adoption.

2. The first explanation of AuctionsPlus' low rate of adoption is the nature of the cattle producers' social system and its character of communication channels. The cattle producers tend to stick to their traditional ways of trading. Since an important part of their social life depends on the traditional saleyard auctions, they are not well disposed towards an innovation which takes away a big part of their social network. In AuctionsPlus' case the early adopters, of whom most were involved in CALM or industry politics, failed to function as 'opinion leaders'. Most rejecters were in no way personally connected to these early adopters, which contributed to the gap between relative advantage experienced by users and the individual decision process of potential users only informed by mass media. In a later phase the system was taken over by major agents who haven't stimulated adoption.

3. The second explanation is the kind of innovation decision to be made and power distribution in the industry. As shown in the AuctionsPlus case, Kambil and van Heck's process-stakeholder framework does not suit the situation in which the adoption decision is optional. Their analysis focuses on an innovation decision which is collectively made by or made by an authority and then implemented. Power distribution among stakeholders can be of major impact on an innovation's rate of adoption. Most stock agents (non-owners) do not stimulate adoption of the system and it is especially remarkable that the agents who took over AuctionsPlus do not seem to stimulate usage of the system. Rogers does not mention the possibility of such 'negative change agents'.

4. The third explanation is the lack of critical mass. In the AuctionsPlus case, a critical mass of adopters has not been reached -at least not fast enough. When the system was first launched no network effects have taken place, which is linked to the "failing opinion leaders' mentioned earlier. Adoption has not accelerated; this is a 'chicken and egg problem'; no potential user will adopt until enough others have adopted. 


\subsection{Discussion on the Research Model}

As a result of the conclusions from the case study the research model can be revised by adding important factors found. This revised research model is shown in Figure 3.

The factors added to the research model are: social system, communication channels, industry context and critical mass.

The nature of a social system plays an important role in the adoption of B2B electronic marketplaces. Electronic commerce is often marketed as making business locations irrelevant. Change agents launching B2B electronic marketplaces should comply with social networks though, which are of great importance in many industries. Social involvement is often a way to transact effectively. This social aspect of traditional ways of trading is not (easily) exchangeable with IT-enabled innovations, which claim to offer more efficiency. This argument is supported by recently published literature. Steinfield argues that the success of local business clusters depends on the exploitation of 'social capital - proximity affords interaction opportunities, common language and culture enhance share understanding, relationships facilitate knowledge sharing yielding innovation, and trust arising from relationships lubricates commerce and reduces transaction costs' (Steinfield, 2002), p. 8). Steinfield states that most B2B electronic marketplaces are 'relatively opaque to - or even worse, attempt to substitute for - social information' (Steinfield, 2002, p. 8) and claims this is a reason why local business clusters do not widely adopt B2B electronic marketplaces. Wellman (2001) and Christiaanse and Markus (2002) also argue for this social network view.

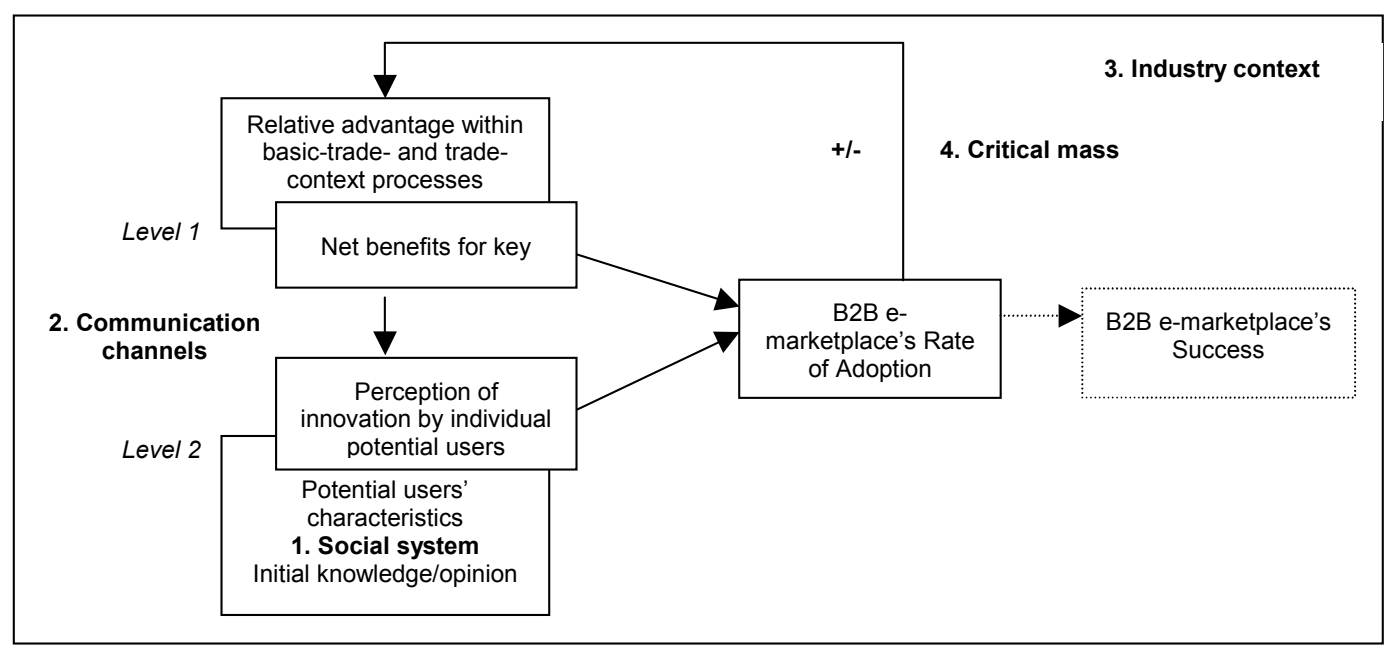

Figure 3: Revised Research Model

Communication channels are of great importance in the adoption of B2B electronic marketplaces. The connection between early adopters who 'should' function as opinion leaders and potential users is an interesting phenomenon linked to social networks which can be investigated more.

An industry's context and power relations among stakeholders can considerably influence adoption of B2B electronic marketplaces. For instance, the case where one stakeholder has a monopolistic position is different from a competitive industry context. Some stakeholders may have a leading or forcing role in an industry which may affect others' innovation decisions. Generally, environmental factors like economic, socio-cultural, and competitive forces, to a great extent affect take up of innovative initiatives in industries. 
Finally, a critical mass of marketplace participants has to be reached quickly enough to accelerate adoption. The value of a B2B electronic marketplace is a function of its number of users; value $=\mathrm{f}$ (\# users). If value is not created quickly enough, the marketplace risks being considered unsuccessful and not worth participating in.

\section{Final Remarks}

There are some limitations regarding the research presented in this paper. Initially, the Australian beef industry context was underexposed regarding stock agents, who turned out to play an important role in the exchange mechanisms discussed. It would be a contribution to investigate their role in these exchange mechanisms and their influence on cattle producers more precisely. In this paper it has become clear that the major stock agent companies owning AuctionsPlus possibly function as 'negative change agents'. This is an interesting finding that could be studied in further research.

Facts on AuctionsPlus adoption and its distribution over Australia unfortunately were difficult to obtain. It would be interesting to gather this information in order to confirm the relation between characteristics of cattle producers and adoption of AuctionsPlus.

The conclusions drawn from the remainder of the conducted research are thought to be valid since several data collection methods were used to investigate factors that affect the rate of adoption of $\mathrm{B} 2 \mathrm{~B}$ electronic marketplaces. The absence of quantitative analysis on the economic level is a weakness. The process-stakeholder framework, as developed by Kambil and van Heck (1998), is a suitable method of investigating relative advantage issues but does not provide enough guidance as for measuring net benefits.

\section{References}

AuctionsPlus. (2002). from http://www.auctionsplus.com.au

Christiaanse, E., \& Markus, L. (2002). Business-to-Business Electronic Marketplaces and the Structure of Channel Relationships. Paper presented at the Twenty-Third International Conference on Information Systems, Barcelona.

Clarke, R., \& Jenkins, M. (1993). The Strategic Intent of On-line Trading Systems. Journal of Strategic Information Systems, 2(1).

Davis, F. D. (1989). Peceived usefulness, perceived ease of use, and user acceptance of technology. MIS Quarterly, 13(3), 319-339.

Davis, F.D., Bagozzi, R.P., and Warshaw, P.R. (1989). User acceptance of technology: A comparison of two theoretical models. Management Science, 35(8), 982-1003.

Fishbein, M. and Azjen, I. (1975). Belief, attitude, intention and behavior: An introduction to theory and research. Reading, MA: Addison-Wesley.

Driedonks, C.F. (2003). Explaining B2B e-marketplaces' Rate of Adoption: A Case Study in the Australian Beef Cattle Industry, University of Twente, Enschede

Fong, T., Fowler, D. \& Swatman, P.M.C. (1998). Success and Failure Factors for implementing Effective Electronic Markets. Electronic Markets, 8(1), 45-47. 
Kambil, A., \& van Heck, E. (1998). Reengineering the Dutch Flower Auctions: A Framework for Analyzing Exchange Organizations. Information Systems Research, 9(1), 1-19.

Kaplan, S., \& Sawhney, M. (1999). B2B E-commerce Hubs: Towards a Taxonomy of Business Models. University of Chicago, Chicago.

Koppius, O. R. (2002). Information Architecture and Electronic Market Performance. Erasmus University Rotterdam, Rotterdam.

Miles, M. B., \& Huberman, A. M. (1994). Qualitative Data Analysis (Second Edition ed.). United States: SAGE Publications.

Riley, R., Gleeson, T., Martin, P., \& Delforce, R. (2001). Australian Beef Industry 2001, Report of the Australian Agricultural and Grazing Industries Survey of Beef Producers (No. 01.8). Canberra: ABARE.

Rogers, E. M. (1995). Diffusion of Innovations (4th edition ed.). New York: Free Press.

Steinfield, C. (2002). Conceptualizing the Role of Collaborative E-Commerce in Geographically Defined Business Clusters.

Wellman, B. (2001). Computer Networks as Social Networks. Science, 293, 2031-2034.

Wigand, R., Picot, A., \& Reichwald, R. (1997). Information, Organization and Management: Expanding Markets and Corporate Boundaries. Chichester, England: John Wiley \& Sons Ltd.

Yin, R. K., \& Campbell, D. T. (1989). Case Study Research: Design and Methods. Newbury park, CA: Sage Publications. 